\title{
Supply Chain Risk Assessment and Mitigation Approaches for Small-Sized Road Construction Projects
}

\author{
P.T. Ranil. S. Sugathadasa, R.P.H.M.A. Herath and A. Thibbotuwawa
}

\begin{abstract}
Construction industry is impacted by low productivity, high cost and time overruns, quality-related problems, project failures. But the small-scale construction industry is less complex than large scale constructions that has characteristics as a medium amount of investment and a continuously existing industry. The stakeholders who are contractors, technical officers, minor level engineers have faced more risks and disruptions during a project due to various type of threats. This study expects to identify, assess risks, and provide steps to mitigate risks. The supply chain is an innovative philosophy which is integrated with every operation to deliver the final product with the right time, right cost, and right quality. Currently, the small-scale construction sector has to deliver the final product within a limited time and cost framework. Within the given time frame, the contractor needs to manage his project with necessary standards parallelly making profits. Unawareness of risk management concepts in minor level industries has resulted in time and cost overruns. In this study, one of popular methods which is the risk matrix was used to assess the risks. The probability of occurring of the given risk factor and impact on the project were noted down as time, cost, and quality. Risk mitigation strategies were proposed based on current practices identified from the industry and reviewing previous literature.
\end{abstract}

Keywords: Small-scale road construction supply chain, Small-scale construction risk, Risk assessment, Mitigation strategies

\section{Introduction}

The construction industry demonstrates a complex and dynamic nature because of its complexity. As a minor part of it, small-scale road construction projects are critical nowadays because the industry is facing more repercussions due to major project failures, project delays, quality-related problems and the high influence of political bodies.

Risk assessment is a term used to describe the identification of hazards (risk identification) and risk factors which have the potential to harm and analyse and evaluate (risk evaluation) the risk associated. Risk mitigation is a strategic approach to reduce the effects of threats and risk mitigation takes steps to minimize the effects. Risk management can be expressed as undertaking possible steps to diminish the level of probability and impact on risks [1-3].

The small-scale road construction industry is needed to be more structured because it has a limited timeframe and estimated budget. Therefore, a contractor should manage the construction process within a given framework while making profits. This study searched for the need of supply chain risk assessment (SCRM) concept to employ the concept more efficiently to minimize the unwanted costs throughout the project $[1,4]$.

The ultimate purpose of this research is to identify "What are the major and minor risk factors in small scale road construction supply chain in Sri Lanka and possible risk mitigation strategies?". Below stated research questions were generated to reach its objectives.

Eng. (Dr.) P.T. Ranil. S. Sugathadasa

B.Sc.(Hons)(Moratuwa), MSc.Eng (Moratuwa), MBA

(Colombo), PhD (Moratuwa), CEng, PMP, MIE(SL), Senior

Lecturer, Department of Transport and Logistics

Management, University of Moratuwa.

Email:ranil.sugathadasa@themotivator.lk

(iD) https://orcid.org/0000-0002-2841-8332

Mr. R.P.H.M.A. Herath

B.Sc.(Hons)TLM (Moratuwa)

Undergraduate, Department of Transport $\mathcal{E}$ Logistics

Management, University of Moratuwa.

Email:akalankahera@gmail.com

(D) https://orcid.org/0000-0002-4132-6360

Dr. A. Thibbotuwawa

B.Sc.(Hons)(Moratuwa), MSc.Eng (IMT-France),PhD.Eng (AAU-Denmark), MIEEE, Senior Lecturer, Department of

Transport and Logistics Management, University of Moratuwa.

Email:amilat@uom.lk

(D) https://orcid.org/0000-0002-5443-8839 
Q1) How can supply chain management (SCM) be employed in small scale road construction projects in Sri Lanka?

Q2) What are the negatively affecting factors on the supply chain of Sri Lankan small-scale road construction industry?

Q3) What is the optimized approach for assessing and mitigating risks?

\subsection{Small-scale Road Construction Industry}

Small scale road construction industry plays an indispensable role in Sri Lanka since the primary infrastructure development is essential to increase mobility and access issues in both rural and urban areas. A considerable amount from the annual budget has been allocated for minor scale road construction projects. Disruptions and delays during the project life cycle are one of the major problems due to the complexity of procurement and operation processes. Project failures and delays in the construction supply chain have been increasing in the last decade.

Planning and development of A, B and E class roads are responsible for Road Development Authority in Sri Lanka. The rest of C, D class roads are developed and maintained by provincial governments and government secretarial offices. C and D class roads were taken for the study as small-scale road constructions. Below figure indicates the supply chain process of small-scale road construction sector.

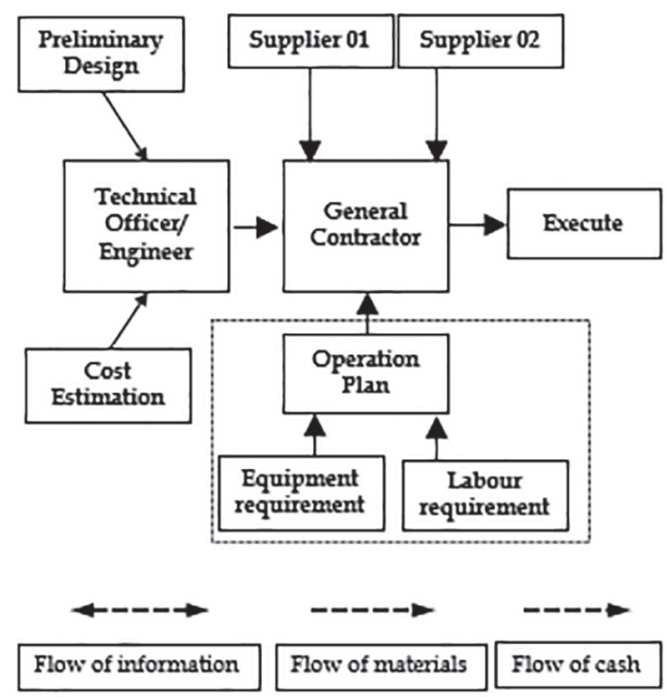

Figure 1 - Small-Scale Construction Process

\section{Literature Review}

\subsection{Supply Chain Management (SCM)}

Supply chain management concept is extracted from the supply chain concept. The supply chain is a network of facilities such as purchasing raw materials, converting them into intermediate products and final products, and delivering products to consumers through a distribution system [2]. Basically, supply chain management is a part of a management philosophy that relates to link production, distribution of a product by cutting excess costs and deliver final products quickly to the ultimate customers. This is done by controlling internal inventories and production, sales and mass warehouses of firm vendors [3-5].

\subsection{Construction Supply Chain Management}

SCM is a vital tool in the manufacturing industry and it controls business processes systematically to improve quality and save time [4]. Construction Supply Chain in large scale projects has large complexities due to the involvement of parties.

\subsection{Risk Management (RM)}

Construction is a complex and challenging process. Among other things, it requires the interpretation and compliance of many regulations. The accumulation of significant resources and coordination with numerous parties such as owners, design professionals, contractors and subcontractors may have different goals and objectives. In addition, many factors are unknown or unknown at the beginning of any project. Unsurprisingly, risks are an expected part of this process $[1,6]$.

Following tools and techniques have been mentioned to identify the key risk factors at the primary stage by the project management body of knowledge. A construction risk can be described as any exposure to possible loss because every construction project is different from previous ones. Therefore, the contractor should be able to associate with those risks to ensure the success of a project [3]. Risk management can be defined as the process of identifying, analysing and managing the risks through providing appropriate guidelines against identified threats intended to impact level on project time, cost and quality [7].

Risk identification is the initial step of the SCRM process because of remaining steps depended on it. It is crucial to identify the 
supply chain process of the construction process and its characteristics because every possible single risk can result in positive or negative consequences on the project [8]. Identification of risk factors is based on interviews, discussions with industry experts and past research studies that are related to supply chain risks. This research was carried out with 30 published research works. Only a few literature is available from other countries that are widely used to identify necessary main risk factors and sub risk factors related to Sri Lankan construction context. Numan Aloko searched for the factors that cause cost overruns in the construction industry in Afghanistan [9]. Also, Paweł Szymańskia explored the circumstances of project delays. The above mentioned researchers have identified the most influential factors for cost overruns and delays in the construction sector [10].

Specifically, the general contractor's internal risks include technical and organizational risks, and management and financial risks. The general contractor's exterior risks include political and social risks, and economic and legal risks. The risks of engineering design subcontractor include risks of construction and structure design, and coordination risks with other organizations. The risks of project construction subcontractor include time risks, quality risks, cost risks, and construction safety risks. The risks of materials and equipment supplier include credit risks, price variation risks, and contract implementation risks [11].

Organizations have used various types of data collecting methods for the identification of risk factors. Brainstorming, questionnaire survey, delphi technique, interviewing or expert opinion, risk breakdown structure (RBS), checklists and assumption analysis are the most popular techniques used to collect data [1,3]. Questionnaire survey is one of widely used qualitative data collection tool to obtain data that have the ability to solve statistically. It can be created for a group of people or population. The main advantage is that it can be made to satisfy a particular purpose. It reflects the view of the participant [12].

Risk identification tool is based on historical information, knowledge and experiences obtained from previous similar projects. It offers the quickest, simple, cost-effective method for identification of risks. The main disadvantage of a checklist is that the user is limited to the risk factors on the checklist because it is impossible to create expanded and more comprehensive checklists [12].

Identify factors pertaining to supply chain risks as environmental factors, industry factors, organisational factors, problem-specific factors and decision-maker related factors. Apart from the above, classifications based on the level of decision making in a supply chain or the level of risk mitigation strategy are also meaningful. Viewing from this point, supply chain risks can be classified into operational level risk, tactical level risk, strategic level risk. This classification will enable the decision makers to visualise the impact of various risks more precisely and thus to frame mitigation strategies more effectively [13].

After identification of the risk factors, evaluation tools and techniques intended to measure the probability of occurrence of risks and impacts on the project should be indentified. The fundamental purpose of this stage is to prioritize the risk factors based on the scoring system. Risk assessment provides a platform to identify high-risk factors and lowrisk factors for project stakeholders for decision making [14].

The risk matrix or the decision-making matrix is merging information such as consequences of an event in the case of occurrence, and the events probability of occurrence, to quantify the risk. Decision Tree Analysis is a graphical technique which aims to choose the best possible option by means of considering and comparing various situations and consequences. The analysis includes the cost of choices and probability of occurrence, then allocates a value and outcome [15].

There are several mathematical methods that focus on risk probability assessment. They basically allow to formalize imperfect knowledge and analyse the risks associated with the inability to anticipate the future. However, the main methods include, PERT method, Decision trees, Probabilistic methods and Probability theory, Fuzzy sets, Artificial neural networks. Sensitivity analysis is mainly done to find out which risks are the most influential on the project. In fact, the sensitivity of the model (of the project) to changes in the structure and different parameters is determined in this method [10].

Through a risk probability and impact assessment, the likelihood of a defined risk to 
occur is evaluated. Risk impact on a project is assessed regarding its negative effects which result from threats. For that, clear definitions in each degree of probability and impact scale should be needed to increase the accuracy of data. After assessing the probability and impact, the average of the probability and impact is computed to prioritize the risk factors. Ratings are used to classify the risks in order of their nature of occurence [16].

$$
\text { Risk= Probability * Impact }
$$

Time, cost and quality are three critical objectives in construction project planning that are completely independent factors but complexly related. The ultimate objective of considering time, cost and quality is to set up the minimal time, cost and risk while enhancing the quality [17]. The probability impact matrix is a commonly used risk assessment tool [18]. It is an easily understandable tool which is contributed to identify, manage and control risks. With regard to the level of risks, colour codes can be allotted to indicate the low, medium and high risks. According to the score of a particular risk factor, the desired response strategy will be proposed [19]. Identified critical, moderate and negligible risk factors will be used to create proper response strategies. Mitigation strategies will be proposed for more critical risk factors to minimize the risk impact should the risk occur, avoid techniques proposed for moderate risks to act on taking some sort of action or put plans in place that will greatly reduce the likelihood of the risk event happening and rest of negligible risk factors can be accepted [14].

\section{Methodology}

In this study, it is expected to survey and provide approaches for incorporation of supply chain management in small scale road construction projects in Sri Lanka, along with identifying risk factors affecting the implementation of SCM in small scale road construction industry. For the study, purposive sampling also known as subjective sampling method was used for accessing a particular subset of people relying on own judgment.

The aims of the research, supply chain risk assessment and mitigation approaches for small-sized road construction projects, are achieved through the above mentioned four objectives.
The below stated process flow chart provides great explanation of research process. Each step is explained comprehensively in research.

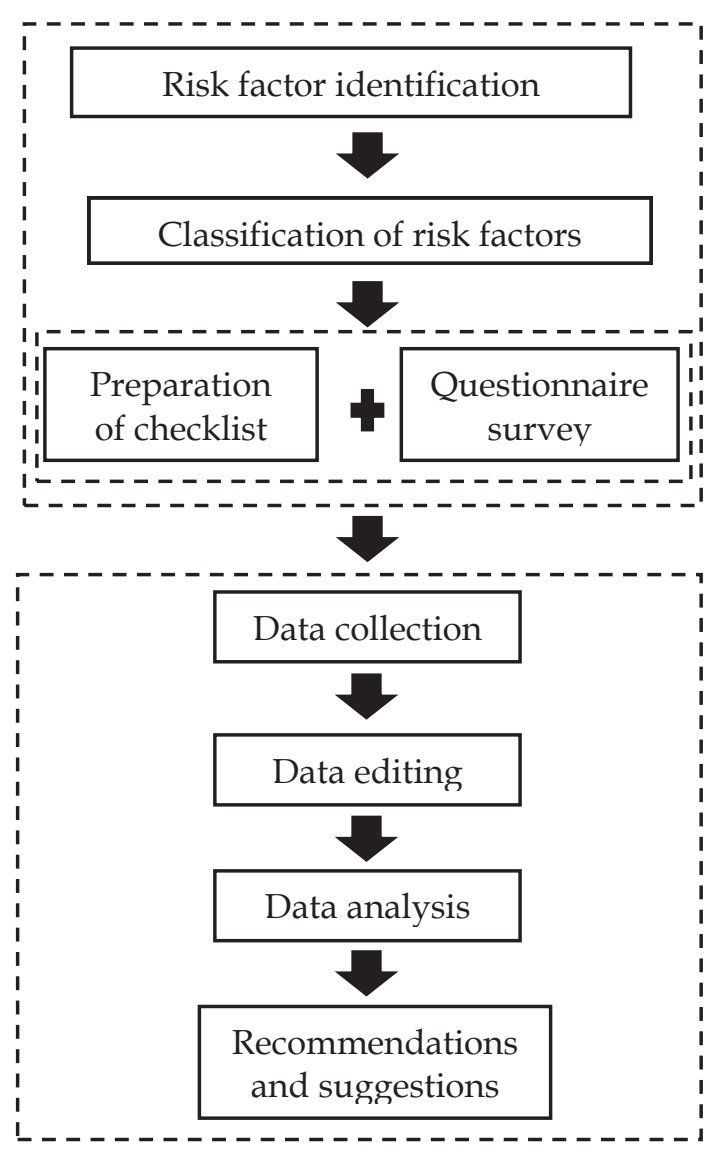

Figure 2 - Research Process

\subsection{Identification of Risks}

As the first step, according to past literature and expert interviews, twelve main risk factors and twenty-three sub risk factors were discovered.

The second step of the methodological process involves classifying the identified risk factors in order to stage the risk for risk breakdown structure (RBS). In project management, RBS is considered as the hierarchical representation of risks. In keeping with RBS, identified risk factors are segmented into supply and operation. Then risk factors were categorized accordingly. As supply main risk factors, material delays, improper use of machines and equipment, lack of material knowledge, improper selection of suppliers, loss due to material condition and wastages and difficulties to place an order at the project location were identified.

Factors which are associated with raw materials, improper planning and scheduling, 
poor workforce utility, project delays, lack of time management and project failures have been identified as operational risk factors. These major risk factors were further broken down to sub risk factors to enhance the depth of the study and to find the root cause related to the main risk factor as well.

\subsection{Data Collection}

To collect the necessary data for this study, a checklist and questionnaire was created and distributed to the respondents in selected areas in Sri Lanka. Respondents had been selected from three secretarial divisions in Matale, Dambulla and Kurunegala in Sri Lanka. With the purpose of collecting survey data, 93 respondents were selected. Persons who have expert knowledge in the field were focused to distribute the research instruments. For that, engineers, technical officers, small-scale contractors were selected as respondents. Above mentioned parties are only involved in small scale construction sector operations mostly in Sri Lanka and they provided adequate knowledge to conduct the study.

Data was gathered by face-to-face discussions with relevant persons with the purpose of a better understanding of the SCM concept and risk management. For that purpose, verbal information and instructions were provided.

The checklist comprises two types of risk factors such as main risk factors and sub risk factors. Moreover, risk factors have been divided into their applications as supply and operation. The checklist is the major research instrument and provides raw data for further analysis. Two Likert scales were developed, and five levels were included to gather the probability level and impact level on time, cost and quality based on the standard risk matrix as follows. A questionnaire was designed to gather relevant information from the respondents.
Table 1 - Scale of Probability

\begin{tabular}{|l|l|l|l|l|l|}
\hline $\begin{array}{l}\text { Probabi } \\
\text { lity }\end{array}$ & Very low & Low & $\begin{array}{l}\text { Moderat } \\
\text { e }\end{array}$ & High & $\begin{array}{l}\text { Very } \\
\text { High }\end{array}$ \\
\hline $\begin{array}{l}\text { Risk } \\
\text { Event }\end{array}$ & $\mathbf{1}$ & 2 & 3 & 4 & 5 \\
\hline $\begin{array}{l}\text { Extremely } \\
\text { rare } \\
\text { opportunit } \\
\text { y to } \\
\text { occurring, } \\
\text { with } \\
\text { almost no } \\
\text { probability } \\
\text { of } \\
\text { occurring }\end{array}$ & $\begin{array}{l}\text { Risk that } \\
\text { relatively } \\
\text { uncomm } \\
\text { on, but } \\
\text { have a } \\
\text { small } \\
\text { chance of } \\
\text { occurring } \\
\text { typical } \\
\text { risk } \\
\text { factors, } \\
\text { with } \\
\text { about a } \\
\text { 50/50 } \\
\text { chance of } \\
\text { taking } \\
\text { place }\end{array}$ & $\begin{array}{l}\text { Risks } \\
\text { that are } \\
\text { highly } \\
\text { likely to } \\
\text { occur }\end{array}$ & $\begin{array}{l}\text { Risks } \\
\text { that are } \\
\text { almost } \\
\text { certain } \\
\text { to occur }\end{array}$ \\
\hline
\end{tabular}

Table 2 - Scale of Impact

\begin{tabular}{|c|c|c|c|c|c|c|}
\hline \multirow{2}{*}{$\begin{array}{l}\text { Identif } \\
\text { ied } \\
\text { Risk }\end{array}$} & \multirow{2}{*}{ Impact } & $\begin{array}{l}\text { Very } \\
\text { low }\end{array}$ & Low & $\begin{array}{l}\text { Modera } \\
\text { te }\end{array}$ & High & $\begin{array}{l}\text { Very } \\
\text { High }\end{array}$ \\
\hline & & 1 & 2 & 3 & 4 & 5 \\
\hline \multirow{3}{*}{$\begin{array}{l}\text { Risk } \\
\text { Event }\end{array}$} & Time & $\begin{array}{l}\text { Insignifi } \\
\text { cant } \\
\text { time } \\
\text { increase }\end{array}$ & \begin{tabular}{|l|}
$<3-$ \\
hour \\
non- \\
workin- \\
g
\end{tabular} & $\begin{array}{l}<1 \text {-day } \\
\text { non- } \\
\text { workin- } \\
\mathrm{g}\end{array}$ & $\begin{array}{l}\text { 1-3-day } \\
\text { non- } \\
\text { workin- } \\
\text { g }\end{array}$ & $\begin{array}{l}\text { More } \\
\text { than } 3 \\
\text { days }\end{array}$ \\
\hline & Cost & $\begin{array}{l}\text { Insignifi } \\
\text {-cant } \\
\text { cost } \\
\text { increase }\end{array}$ & $\begin{array}{l}<10 \% \\
\text { cost } \\
\text { increase }\end{array}$ & $\begin{array}{l}10-20 \% \\
\text { cost } \\
\text { increase }\end{array}$ & $\begin{array}{l}20-40 \% \\
\text { cost } \\
\text { increase }\end{array}$ & $\begin{array}{l}>40 \% \\
\text { cost } \\
\text { increas } \\
\text { e }\end{array}$ \\
\hline & Quality & $\begin{array}{l}\text { Disrupti } \\
\text { ons that } \\
\text { can be } \\
\text { generall } \\
\text { y } \\
\text { ignored }\end{array}$ & $\begin{array}{l}\text { Quality } \\
\text { degrada } \\
\text { tion } \\
\text { barely } \\
\text { noticeab } \\
\text { le }\end{array}$ & \begin{tabular}{|l|} 
Negativ \\
e \\
quality \\
issues \\
can \\
manage \\
by \\
verbally
\end{tabular} & $\begin{array}{l}\text { Quality } \\
\text { standar } \\
\text { ds are } \\
\text { meagre } \\
\text { level }\end{array}$ & \begin{tabular}{|l|} 
The \\
final \\
produc \\
$\mathrm{t}$ is \\
unacce \\
ptable
\end{tabular} \\
\hline
\end{tabular}

\begin{tabular}{|l|l|l|}
\hline Colour & Category & Explanation \\
\hline & Negligible & $\begin{array}{l}\text { Risks can be generally } \\
\text { ignored }\end{array}$ \\
\hline & $\begin{array}{l}\text { Risks have a moderate } \\
\text { impact and moderate } \\
\text { probability level to } \\
\text { occur }\end{array}$ \\
\hline & Critical & $\begin{array}{l}\text { Risks that are very } \\
\text { critical }\end{array}$ \\
\hline
\end{tabular}


Risks can be ranked and prioritized as shown in Table 3 by using different colours, each colour category specific to the stated risk level.

After scoring and prioritizing identified risk factors, it is needed to explore proper strategies to mitigate risks. Investigated risk response methods have been proposed as below according to the nature of the risk factor. The proposed strategies to respond to the risks are mitigation, avoidance and acceptance.

Table 4 - Colour Index

\begin{tabular}{|l|l|l|}
\hline $\begin{array}{l}\text { Nature of } \\
\text { risk }\end{array}$ & Response & Steps to take \\
\hline $\begin{array}{l}\text { Critical } \\
\text { risk } \\
\text { factors }\end{array}$ & Mitigation & $\begin{array}{l}\text { Minimize the risk } \\
\text { impact should the } \\
\text { risk occur }\end{array}$ \\
\hline $\begin{array}{l}\text { Moderate } \\
\text { risk } \\
\text { factors }\end{array}$ & Avoidance & $\begin{array}{l}\text { Act of taking } \\
\text { some sort of } \\
\text { action or setting } \\
\text { plans in place that } \\
\text { will greatly } \\
\text { reduce the } \\
\text { likelihood of the } \\
\text { risk event even } \\
\text { happening }\end{array}$ \\
\hline $\begin{array}{l}\text { Negligible } \\
\text { risk } \\
\text { factors }\end{array}$ & Acceptance & $\begin{array}{l}\text { Not taking any } \\
\text { other action in } \\
\text { order to reduce } \\
\text { the risk because } \\
\text { we can accept its } \\
\text { impact, } \\
\text { possible the } \\
\text { consequences }\end{array}$ \\
\hline
\end{tabular}

\section{Data Analysis and Findings}

The ultimate objective of this qualitative analysis was to score the risk factors based on respondents' given numbers according to the Likert scale and then prioritize the risks accordingly. To calculate the final risk score, average risk scores were calculated considering time, cost and quality separately. Thirty responses were received for analysis.

In this research, 12 main risk factors and $23 \mathrm{sub}$ risk factors were identified and classified. Qualitative analysis is the proposed technique for analysis which offers a set of benefits such as cost-effectiveness, least time consumption and rapidness. The goal of qualitative analysis is to score the risk factors based on the participant's response according to the Likert scale and then prioritize the risks accordingly. To calculate the final risk score, average risk scores were calculated considering time, cost and quality separately. After prioritizing identified critical risks according to the time, cost and quality, parameters were indicated in the below figures separately. Moreover, mitigation strategies have been proposed to lessen the impact on the project.

\subsection{Discussion on Checklist}

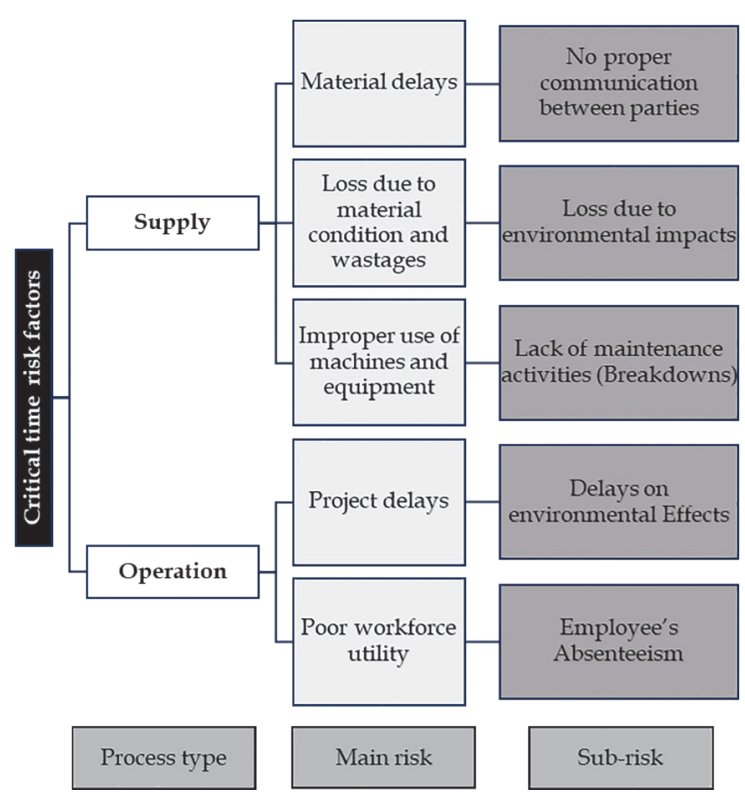

Figure 3 - Critical Time Risk Factors

Risk factors shown in Figure 3 were identified as critical risk factors that impacted the project time.

Material delays in small sector construction projects due to inadequate coordination and weakness of information sharing have a high occurrence probability. The major factor is not having proper communication among contractors, workers, and suppliers. Therefore, proper information sharing methods is needed. Parties involved in small scale construction industry share the information through mobile devices. Therefore, smart devices such as smartphones can be used to share the exact location.

Delays due to weather situations are obviously outside the control of contractors and others. Delays can occur due to unfavourable weather in both supply of the materials and during the project operation. It may establish losses of material widely. Mainly, weather conditions change from region to region due to the effect of monsoons. Therefore, parties should try to minimize these disputes by providing detailed 
weather reports with weather variations to regional wise.

Due to lack of maintenance activities of machines, such as mixers, concrete forks, concrete finishing, tamping rammers, they lead to breakdown during operations. These will result in major time delays to the project.

It is important to continue maintenance activities to prevent future threats and disruptions. Preventive maintenance management is one of the key areas developed for large-scale construction projects. Some of the strategic methods that can be followed to mitigate the risks according to Preventive Maintenance Management (PMM) are daily pre and post-operative checks, frequent cleaning, and assigning a permanent operator to the machine.

Employee absenteeism is one of the critical issues in construction and frequent absence may have serious repercussions. Various reasons are identified as causes of absenteeism among labourers in rural orientation. Particularly, work fatigue, unhealthy working conditions, alcoholism are the identified major causes. It reflects the loss in time and production widely in small sector construction projects.

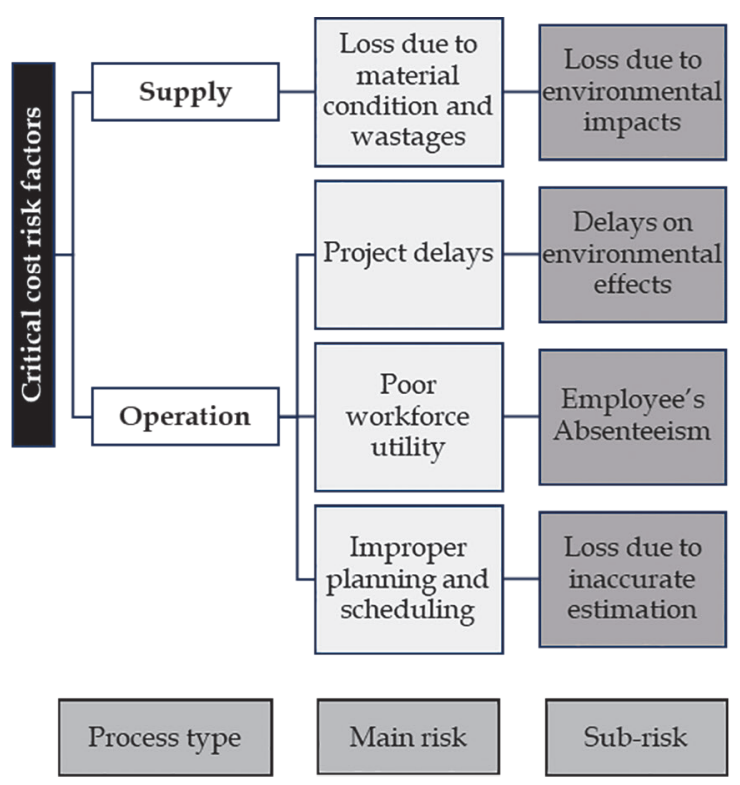

Figure 4 - Critical Cost Risk Factors
To overcome this issue, an appropriate size of workforce should be assigned to the project to reduce the work fatigue of labourers. The main contractor needs to arrange the work with flexible hours and should pay overtime to employees. Furthermore, the contractor should appoint team leaders and should transfer responsibility to leaders to confirm the attendance of labourers on every working day. Improve workplace morale is one strategy that can be used to increase the engagement of the people. Figure 4 stated risk factors were identified as high-risk factors that impacted to the project cost.

Cost overruns are more critical in road construction projects. When projects are delayed, it will incur additional costs. The labourers get paid on a daily basis payment method in small-scale road construction projects. Therefore, the non-working period is also included in daily payments. Environmental effects are led to high overhead costs such as daily rental of machines and equipment. Also, material costs will occur due to wastages. During the rainy season, material cost is somewhat higher than in the other periods. Therefore, the contractor should be able to manage his project parallelly with the weather reports. Absenteeism is a critical issue involved in small-scale construction sector projects. Usually, manpower labourers work throughout the project. Therefore, the abovementioned strategies can be used to mitigate this type of issue.

Error estimation can happen from both contractor and government bodies. Small-scale construction projects are heavily dependent on the cost factor. Thus, a small impact could create huge losses to the contractor. Keeping employees waiting due to error estimation of materials will incur a huge cost to the contractor. Once a contract is made between the parties, legally everyone needs to perform accordingly. When estimating a project cost, the below-stated factors must be considered to increase the accuracy of the planning process, market conditions, project complexity, weather, size of contract, site constraints and resource availability.

Figure 5 represents the most critical risk factors regarding the quality of a construction project. 


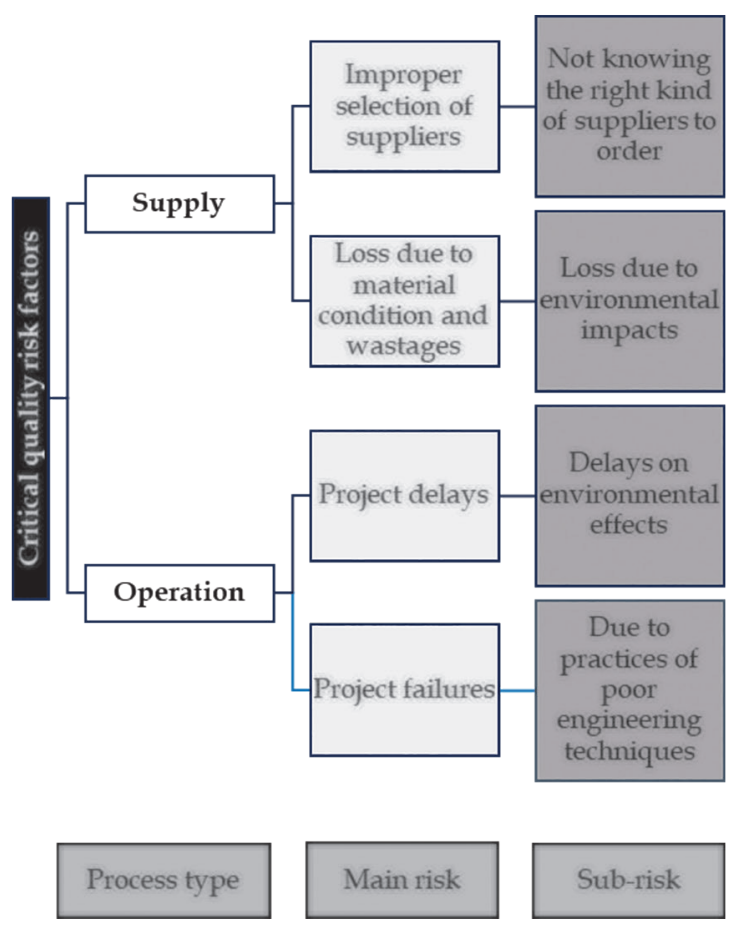

Figure 5 - Critical Quality Risk Factors

Environmental impacts are considered as noncontrollable threats on projects [20]. Achieving quality in construction is tough and inefficient or fewer practices of quality will result in great loss of money, time and resources. Avoidance of project scheduling during bad weather seasons would lead to high-quality outputs. Employees, engineers, technical officers should rely on weather reports and need to arrange the project plan based on weather forecasts [21].

Poor construction practices lead to failures of existing roads such as water bleeding, cracks, depressions, edge subsidence, rutting, edge damage, local aggregate loss. As possible causes for project failure, poor engineering techniques are significant. Proper removal of the existing surface, grading and sloping methods are led to enhance the foundation of the road. Without proper land preparation, the project will have quality issues. Proper water drainage is another significant issue.

\subsection{Discussion on the Questionnaire}

The questionnaire survey sought the extent to which Sri Lankan small-scale road construction industry is familiar with the supply chain and supply chain risk management. It was provided with general information about the participants and which tools and techniques are used to identify and manage risks in low level construction projects. The questionnaire has been made with the objective of getting the background and current status, supply chain management relevance, tools and techniques used to manage the current risks.

The following graph indicates the number of projects that was carried out by a contractor within a year. Most contractors have done more than 12 projects within a year. An average project time takes less than a month.

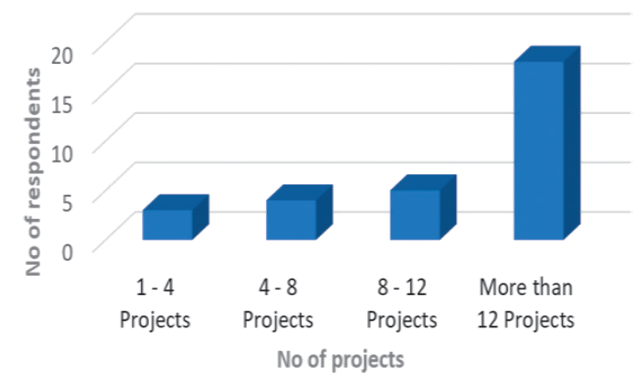

Figure 6 - No of Annual Projects

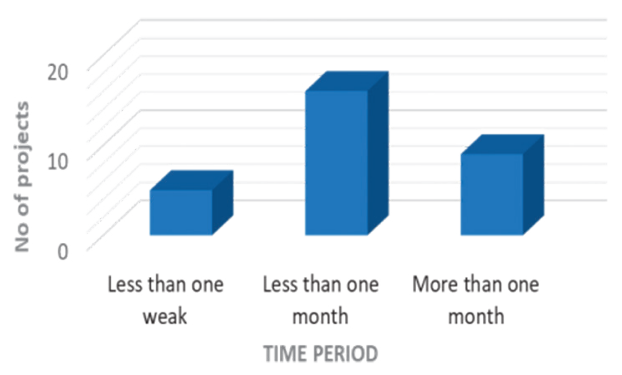

Figure 7 - Average Period of a Project

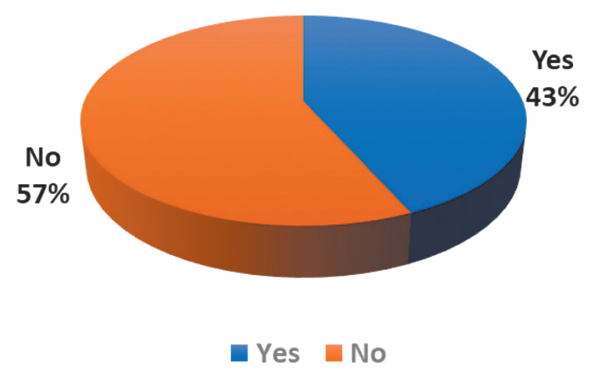

Figure 8 - Project Failures

The questionnaire analysis indicates that a considerable percentage of project failures have occurred due to reasons stated below. Most of them had quality-related problems.

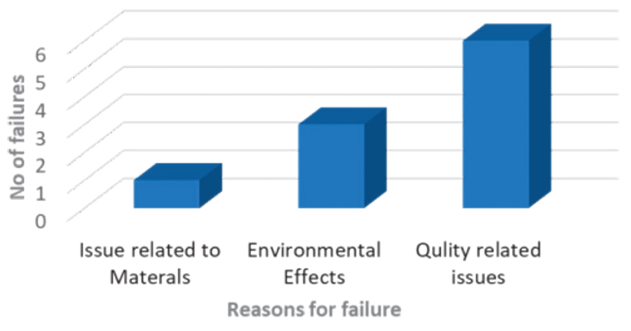

Figure 9 - Reasons for Project Failures 
Figures 8 to 12 represent the respondent's awareness of risk management in the smallscale construction sector.

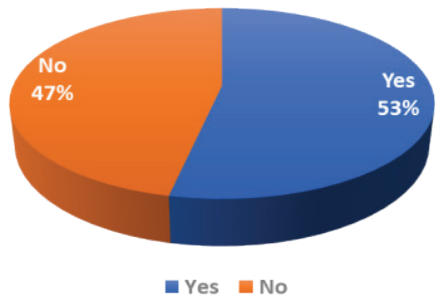

Figure 10 - Losses Occurred due to Unexpected Reasons

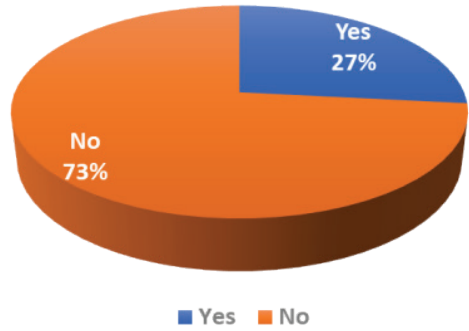

Figure 11 - Awareness of the Risk Management in Small Scale Construction

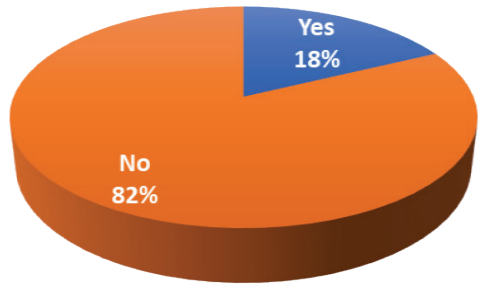

Yes no

Figure 12 - Risk Management Framework Users

One of the significant research findings is the higher political influence on the small-scale construction industry. Even the project requirement was chosen by political bodies. A policy-based project priority list should be needed to evade this issue.

\section{Conclusion and Future Studies}

Throughout the research, the relevance of supply chain management in the small-scale road construction sector in Sri Lanka was investigated. This study searched for the need of SCRM concept and employ it in a more efficient way to minimize the unwanted costs throughout the project life cycle. This study identified the less explored area in the local construction sector and provided some insights. Data analysis and findings indicate a lack of studies in the identified sector. The results have found critical risk factors regarding time, cost and quality. Moreover, moderate risk factors and negligible risk factors have been identified.
According to the analysis, eight highest risk factors were recognized and Sub risk factor which represented highest portion of the main risk according to the calculation had been mentioned (Figure 3, Figure 4, Figure 5). Risk response strategies were proposed based on literature. A risk response framework has been developed corresponding to the small-scale road construction projects. One of the main results is classification and analysis of risk factors according to time, cost and quality. This study provides more insights for contractors to increase profits and enhance awareness of risk management in small-scale construction. Also, this research has provided inputs for project planners to avoid estimation errors.

\subsection{Limitations of the Study}

The absence of previous researches targeting the Sri Lankan context is the main limitation. This limitation was minimized by conducting direct interviews and collecting primary data from the experts in the local industry. This research was limited to 30 responses and the study is mostly based on the expert knowledge of the respondents. Sometimes, responses are not accurate because of the knowledge level, the experience of the industry and ways of realizing the questions.

\subsection{Recommendations for Future Studies}

A further research study can be conducted focusing on the entire small-scale construction industry. The addition of more risk factors to the checklist will enhance the depth of the study.

Supplier selection methods can be arranged with the help of government bodies to increase the quality. Multiple sourcing, collaborations can be introduced to increase the efficiency of the supply chain. Policy-based research is needed to assess the political influence of smallscale construction projects.

\section{References}

1. Sugathadasa, P. T. R. S., "Identification and Modelling of Construction Supply Chain Risk Triggers," PhD Diss., 2018.

2. Perera, S., Perera, H. N., and Kasthurirathna, D., "Value Chain Approach for Modelling Resilience of Tiered Supply Chain Networks," 2017 Moratuwa Eng. Research Conf. (MERCon), 2017, pp. 159-164, doi: 10.1109/ MERCon.2017. 7980474. 
3. Perera, H. N., Thibbotuwawa, A., Rajasooriyar, C., and Sugathadasa, P. T. R. S., "Managing Supply Chain Transformation Projects in the Manufacturing Sector: Case-Based Learnings from Sri Lanka," Research Trans. Logi. Ind. Conf. (R4TLI), R4TLI-D13, 143-146, 2016.

4. Balachandra, K., Perera, H. N., and Thibbotuwawa, A., "Human Factor in Forecasting and Behavioral Inventory Decisions: A System Dynamics Perspective," Int. Conf. Dynam. Logis. 516-526. Springer, Cham, 2020.

5. Perera, H. N., Fahimnia, B., and Tokar, T., "Inventory and Ordering Decisions: A Systematic Review on Research Driven through Behavioral Experiments," Int. J. Operat. Prod. Manag., 2020.

6. Payam, S. and Seyed, A. S. H., “Development of Supply Chain Risk Management Approaches for Construction," Compu. Ind. Eng., 837-850, 2018.

7. Krantikumar, M., "Risk Management in Construction Industry," Int. J. Eng. Research, 153155, 2016.

8. Sugathadasa, R., Wakkumbura, D., and Perera, H., and Thibbotuwawa, A., "Analysis of Risk Factors for Temperature-Controlled Warehouses," Operat. SCM : Int. J., 14(3), 320337, 2021.

9. Mohammad, N. A., "Risk Assessment Process for Construction Projects in Afghanistan," Int. I. Adv. Eng. Res. Science (IJAERS), 213-216, 2018.

10. Paweł, S., "Risk Management in Construction Projects," Poznan University of Technology. ScienceDirect, 174-182, 2017.

11. Zhiqiang, L. and Caiyun, G., "Study on the Risks Management of Construction Supply Chain," Int. Conf. Ser. Opera., pp. 629-632. IEEE, 2009.

12. Mmurat, G. "Construction Safety Risk Assessment with Introduced Control Levels," researchgate, 11-18, 2017.

13. Vishnu, C. R., Sridharan, R., and Ram Kumar, P.N., "Supply Chain Risk Management: Models and Methods," 31-55, 2019.

14. Devdatt, P. P., "Hazard Identification and Risk Assessment in Construction Industry," Int. J. App. Eng. Research, 7642-7643, 2018.

15. Perera, H. N., and Sudusinghe, J. I., "Longitudinal Analysis of Supply Chain Transformation Project Management," 2017 Moratuwa Eng. Research Conf. (MERCon), 2017, pp. 153-158, doi: 10.1109/MERCon.2017.7980473.
16. Ewelina, G., "Risk Management Practices in a Construction Project - A Case Study," Chalmers University of Technology, 2011.

17. Amin, R., "Time-Cost-Quality-Risk of Construction and Development Projects or Investment," Middle-East J. Sci. Research, 218-221, 2011.

18. Sugathadasa, R., De Silva, M. L., Thibbotuwawa, A. and Bandara, K. A. C. P., "Motivation Factors of Engineers in Private Sector Construction Industry," J. App. Eng. Science, pp.1-12, 2021.

19. Robert, D. S., "A Risk Management Framework for Supply Chain Networks," Logis. Ins. Asia Passifc, 2017.

20. Perera, S., Perera, H. N., and Kasthurirathna, D., "Structural Characteristics of Complex Supply Chain Networks," 2017 Moratuwa Eng. Research Conf. (MERCon), 2017, pp. 135-140, doi: 10.1109/MERCon.2017.7980470.

21. Hewage, Harsha Chamara, H. Niles Perera, and Shari De Baets., "Forecast Adjustments during Post-Promotional Periods," EJOR, 2021. 